\title{
IMPLEMENTASI KEBIJAKAN PENDIDIKAN KARAKTER DI SMP NEGERI 5 MATARAM TAHUN PELAJARAN 2019/2020
}

\author{
Lu'luin Najwa, Pajriatun Najah, Hardiansyah \\ Program Studi Administrasi Pendidikan, FIPP Undikma \\ Email: lu'luinnajwa@ikipmataram.ac.id
}

\begin{abstract}
This study aims to describe the implementation of education character policy at SMP Negeri 5 Mataram, the proponent and the resistor factors, and the effect of education character policy implementation on students. This research used a descriptive qualitative approach. The subject of this study involved: the principal, the student head deputy, the homeroom teacher, the religion teacher, and the counseling teacher. The observation, interview, and documentation are used as data collection methods. Furthermore, the result of this study showed that (1) the implementation of education character policy at SMP Negeri 5 Mataram was implemented by school residents with teaching and learning activities.(2) the proponent factors were an internal factor (student awareness) and an external factor (the cooperation among teachers, employees, conducive neighborhood, and programmed activities). (3) the resistor factors were an internal factor (the student character diversity, the teacher limitedness on education character implementation), the external factor was (the lack of parent supervision on problematic children). (4) The effect of education on character implementation creates self-confidence and discipline.
\end{abstract}

Keywords:Implementation, education character policy

Abstrak: Penelitian ini bertujuan untuk mendeskripsikan implementasi kebijakanpendidikan karakter di SMP Negeri 5 Mataram, faktor pendukung, faktor penghambat dan dampak implementasi kebijakan pendidikan karakter bagi siswa. Penelitian ini menggunakan pendekatan kualitatif dengan metode deskriptif. Subjek dalam penelitian ini meliputi: kepala sekolah, waka kesiswaan, wali kelas, guru agama, serta guru BK. Pengumpulan data menggunakan metode observasi, wawancara, dan dokumentasi. Hasil penelitian ini menunjukan bahwa: (1) implementasi kebijakan pendidikan karakter di SMP Negeri 5 Mataram dilaksanakan oleh warga sekolah termasuk kepala sekolah, guru, dan siswa dengan cara mengimplementasikan pendidikan karakter melalui kegiatan belajar mengajar (2) faktor pendukung implementasi kebijakan pendidikan karakter di SMP Negeri 5 Mataram yaitu faktor intren (kesadaran siswa) dan faktor ekstren (kerjasama antara guru dan karyawan, lingkungan yang kondusif, dan kegiatan yang sudah terprogram).(3) faktor penghambat implementasi kebijakan pendidikan karakter, faktor intren (keberagaman karakter siswa dan keterbatasan guru dalam melaksanakan pendidikan karakter) dan faktor ekstren (kurangnya pengawasan orang tua siswa terhadap anak yang bermasalah). (4) dampak kebijakan implementasi pendidikan karakter menciptakan rasa percaya diri dan kedisiplinan.

Kata Kunci: Implementasi Kebijakan, Pendidikan Karakter 


\section{LATAR BELAKANG}

Salah satu tujuan pendidikan nasional adalah membentuk watak serta peradaban bangsa yang bermartabat dalam rangka mencerdaskan kehidupan bangsa. Kebijakan nasional pembangunan karakter bangsa sebagai salah satu prioritas pemerintah dalam pembangunan nasional, dimana pendidikan karakter ditempatkan sebagai landasan untuk mewujudkan visi pembangunan nasional, yaitu mewujudkan masyarakat berakhlak mulia, bermoral,beretikaberbudaya, dan beradab berdasarkan falsafah Pancasila.

Koesoema (Jaleha 2018:1) menjelaskan penyelenggaraan pendidikan tidak hanya mentransfer ilmu dan pengetahuan serta teknologi kepada peserta didik, melainkan harus diarahkan untuk membangun bangsa yang beradab, bermoral dan berkarakter yang mulia, yang tidak hanya diukur dari segi kecerdasan intelegensia akademik, tapi juga diperlukan kecerdasan emosional dan kecerdasan spritual. Setiap lembaga pendidikan berinovasi dan melakukan pengembangan terhadap program yang terkait dengan pendidikan karakter. Nilai karakter religius, jujur, disiplin, toleran, kerja keras, cinta damai, tanggung jawab harus tercermin dalam prilaku dan habituasi dalam kehidupan sehari-hari (Sulistyowati,2012).

Mencetak siswa dengan nilai akademis tinggi memang tidak mudah, namun mencetak siswa dengan akhlak yang bagus serta memiliki nilai akademis tinggi jauh lebih sulit. Untuk mencetak siswa yang seperti itu diperlukan kesadaran, ketegasan, dan kebiasaan yang baik utamanya dari guru dan kepala sekolahnya agar memberikan contoh yang baik kepada siswa. Guru dan kepala sekolah yang menjadi panutan siswa harus mampu menanamkan nilai-nilai karakter kepada siswa. Untuk menanamkan nilai-nilai tersebut sekolah dapat membuat kebijakan berupa peraturan-peraturan. Salah satu contoh penanaman nilai yang biasa dilakukan adalah melalui kegiatan imtaq, membaca al qura'an sebelum memulai pembelajaran, berdo'a sebelum belajar, dll.

Pendidikan karakter adalah pendidikan budi pekerti plus, yaitu yang melibatkan aspek pengetahuan (cognitive), perasaan (feeling) dan tindakan (action) (Azzet, 2011:27). Secara psikologis dan sosiologis, dalam diri manusia terdapat beberapa unsur yang dapat membentuk 
karakter seseorang. Unsur-unsur ini kadang juga menunjukkan bagaimana karakter seseorang. Unsur-unsur itu antara lain; sikap, emosi, kemauan, kepercayaan, dan kebiasaan (Fatchul Mu'in, 2011:162).Pendidikan karakter tidak hanya dibiasakan di lingkungan sekolah, namun juga harus biasa dilakukan di rumah sebagai tindak lanjut dan sinergi antara pihak sekolah dan orang tua di rumah. Karena selain guru, orang tua adalah orang yang bertanggung jawab terhadap budi pekerti anak-anaknya.

Saat ini generasi muda menghadapi persaingan global, yang mana menuntut mereka untuk memiliki kualitas. Kualitas sumber daya manusia tentunya membutuhkan karakter yang baik. Sebuah penelitian di Amerika mengindikasikan 90\% kasus pemecatan disebabkan oleh perilaku buruk seperti; tidak bertanggung jawab, tidak jujur, dan hubungan interpersonal yang buruk.

Berkurangnya nilai-nilai moral generasi muda saat ini ditandai dengan lunturnya budaya malu. Dengan lunturnya budaya malu ini, para generasi muda tidak segan untuk mencoba hal-hal yang tidak baik seperti; merokok di tempat umum, minum-minuman keras, bahkan narkoba dan juga seks bebas. Beberapa perilaku tidak baik remaja juga terjadi di Mataram, antara lain: ) kekerasan dikalangan siswa, 2) penggunaan bahasa dan kata-kata yang memburuk, 3) ketidak jujuran dalam mengerjakan soal ujian, 4) hilangnya rasa hormat terhadap orang yang lebih tua dan guru.

\section{KAJIAN PUSTAKA}

\section{Definisi Pendidikan Karakter}

Pendidikan karakter adalah suatu sistem penamaan nilai-nilai karakter yang meliputi komponen pengetahuan, kesadaran atau kemauan, dan tindakan untuk melaksanakan nilai-nilai tersebut, baik terhadap Tuhan Yang Maha Esa, diri sendiri, sesama, lingkungan, maupun kebangsaan (Omeri, 2015: 468). Menurut Abidin (2012) pendidikan karakter dimaknai sebagai pendidikan yang mengembangkan nilai-nilai karakter pada peserta didik sehingga mereka memiliki nilai dan karakter sebagai karakter dirinya, menerapkan nilai-nilai tersebut dalam kehidupan dirinya, sebagai anggota masyarakat, dan warga negara yang religius, nasionalis, 
produktif dan kreatif.Shoimin (2014:28) menjelaskan karakter sebagai tabiat, watak, sifat-sifat kejiwaan, ahlak atau budi pekerti yang membedakan seseorang dari pada orang lain.

Subiantoro (2015) menambahkan pengertian pendidikan karakter adalah proses mendidik nilai, budi pekerti, moral dan akhlak yang baik kepada individu agar menjadi manusia seutuhnya yang berkarakter mulia. Jadi, dapat disimpulkan bahwa pendidikan karakter merupakan sistem pendidikan yang mendorong anak didik menanamkan nilai-nilai karakter yang berhubungan dengan ketuhanan, diri sendiri, sesama manusia, dan lingkungan.untuk mendukung perkembangan karakter peserta didik harus melibatkan seluruh komponen di sekolah baik dari aspek kurikulum (The Content Of The Curriculum), proses pembelajaran (The Procces Of Instruction), kualitas hubungan (The Quality Of Relationships), penanganan mata pelajaran (The Handling of Discipline), pelaksanaan aktivitas ko-kulikuler, serta etos seluruh lingkungan(Zubaedi, 2011:14).

\section{Tujuan Pendidikan Karakter}

Sulistyowati(2012:28) mengemukakan bahwa tujuan pendidikan karakter, seperti berikut:

1) Mengembangkan potensi kalbu/nurani/afektif peserta didik sebagai manusia dan warga Negara yang memiliki nilai-nilai budaya dan karakter bangsa.

2) Mengembangkan kebiasaan dan prilaku peserta didik yang terpuji dan sejalan dengan nilai-nilai universal dan tradisi budaya bangsa yang religious.

3) Menanamkan jiwa kepemimpinan dan tanggung jawab peserta didik sebagai geresai penerus bangsa.

4) Mengembangkan kemampuan peserta didik untuk menjadi manusia yang mandiri, kreatif dan berwawasan kebangsaan.

5) Mengembangkan lingkungan kehidupan sekolah sebagai lingkungan belajar yang aman, jujur, penuh kreativitas danpersahabatan serta dengan rasa kebangsaan yang tinggi dan penuh kekuatan

Aspek-aspek pendidikan karakter yang perlu dipelajari dan ditanamkan kepada siswa terdiri dari 9 pilar yang saling terkait, yaitu (Hamid dan Saebani, 2013): 
1. Tanggung jawab (responsibility), menghadapi resiko dari perbuatan yang sudah dilakukan;

2. Rasa hormat (respect), bersikap sopan, etis, dan menghargai orang lain secara proporsional;

3. Keadilan (fairness) meletakkan segala sesuatu sesuai dengan porsinya;

4. Keberanian (courage), berani menegakkan kebenaran;

5. Kejujuran (honesty), menjauhkan diri dari sikap dusta;

6. Displin diri (self-discipline), menjalani kehidupan dengan teratur dan terencana;

7. Kewarganegaraan (citizenship), mengerti dan menjalankan kehidupan sosial sebagai warga negara;

8. Peduli (caring), berempati kepada nasib orang lain;

9. Ketekunan (preseverance), memerhatikan dan mengambil pelajaran positif dari semua pengalaman hidup.

\section{Indikator Keberhasilan Pendidikan Karakter}

Keberhasilan program pendidikan karakter dapat diketahui melalui pencapaian indikator oleh peserta didik, sebagaimana tercantum dalam standar lulusan di setiap sekolah yang meliputi (Mulyasa, 2011:64): 1) mengamalkan ajaran agama yang dianut sesuai dengan tahapan perkembangan manusia; 2) memahami kekurangan dan kelebihan diri sendiri; 3) menunjukkan sikap percaya diri; 4) mematuhi aturan-aturan sosial yang berlaku dalam lingkungan yang lebih luas; 5) menghargai keberagaman agama, budaya, suku, rasa, dan golongan sosial ekonomi dalam lingkup nasional; 6) mencari dan menerapkan informasi dari lingkungan sekitar dan sumber-sumber lain secara logis, kritis, dan kreatif; 7) menunjukkan kemampuan berfikir logis, kritis, kreatif, dan inovatif; 8) menunjukkan kemampuan belajar secara mandiri sesuai dengan potensi yang dimilikinya; 9) menunjukkan kemampuan menganalisis dan memecahkan masalah dalam kehidupan sehari-hari; 10) mendeskripsikan gejala alam dan sosial; 11) memanfaatkan lingkungan secara bertanggung jawab. 


\section{METODE PENELITIAN}

Penelitian ini berupaya mengungkap implementasi kebijakan pendidikan karakter yang ada di SMP Negeri 5 Mataram. Metode penelitian yang digunakan pada penelitian ini adalah metode kualitatif deskriptif. Prosedur penelitian ini menghasilkan temuan-temuan yang diperoleh dari data-data yang dikumpulkan dengan menggunakan beragam teknik. Penelitiandeskriptif kualitatif bertujuan untuk mediskriptifkan data penelitian implementasi kebijakan pendidikan karakter. Untuk memperoleh data tersebut, penelitian ini dilakukan dengan menginterprestasikan kejadian atau peristiwa yangmenggambarkan berbagai kegiatan yang terjadi.

Data yang diperoleh dari penelitian ini bersumber dari dokumen dan narasumber. Narasumber penelitian ini adalah Kepala Sekolah, Wakil Kepala sekolah, Guru Agama, Guru BK, Wali Kelas.

\section{HASIL PENELITIAN}

SMP Negeri 5 Mataram sebagai salah satu sekolah yang menerapkan pendidikan karakter sesuai kebijakan sekolah yang telah di keluarkan oleh Kepala Sekolah dengan keputusan nomer: 196/421.3/SMPN.5/2019 tentang Pembentukan Tim Penguatan Pendidikan Karakter (PPK) SMP Negeri 5 Mataram Tahun Pelajaran 2019/2020. Implementasi kebijakan pendidikan karakter di SMP Negeri 5 Mataram melalui kegiatan rutin dan pembiasaan yang diterapkan kepada siswa dimulai saat tiba di sekolah sampai siswa pulang sekolah.Pelaksanaan pendidikan karakter di SMP Negeri 5 Mataram diwujudkan dalam pembiasaan sehari-hari semua warga sekolah mulai dari pagi sampai pulang sekolah dan juga ada jam tambahan untuk kegiatan ekstrakulikuler. Yang terkait dengan nilai-nilai karakter dilaksanakan secara integratif oleh semua lini sekolah, tidak hanya guru PAI dan BK saja. Untuk pelaksanaan program harian otomatis penanaman karakter melekat kepada tata tertib sekolah, mulai dari kehadiran siswa disiplin waktu, pelaksanaan KBM (kegiatan belajar mengajar), sopan santun, senyum salam sapa, tanggung jawab dalam melaksanakan tugas-tugas dirumah, sholat dhuha, serta sholat dzuhur berjamaah.

Pelaksanan pendidikan karakter tidak hanya ditunjukkan oleh siswa saja, guru yang menjadi contoh bagi siswa melakukan pembiasaan disiplin waktu dengan cara berdiri di depan 
gerbang untuk menyambut dan menyalami siswa yang baru datang. Kemudian beberapa guru yang lain memeriksa siswa-siswi mulai dari pakaian, kuku, kerapian seragam, dan rambut.Khusus pada hari Jum'at siswa dan guru melaksanakan kegiatan Imtaq. Pada saat jam istirahat siswa dan guru melaksanakan kegiatan Sholat Dhuha berjamaah di musholla. Sedangkan pada saat jam istirahat kedua semua siswa, guru dan karyawan wajib melaksanakan sholat dzuhur berjamaah, ditambah dengan dzikir dan doa.

\section{Faktor Pendukung Implementasi Kebijakan Pendidikan Karakter di SMP Negeri 5 Mataram}

Faktor pendukung implementasi kebijakan pendidikan karakter beberapa diantaranya antara lain: lokasi yang strategis dan lingkungan sekolah yang kondusif sehingga terciptanya suasana belajar yang menyenangkan, kerjasama guru dan stakeholder dalam membuat kedekatan dengan siswa melalui nasehat-nasehat.

\section{Faktor Penghambat Implementasi Kebijakan Pendidikan Karakter di SMP Negeri 5 Mataram}

Tanggung jawab pendidikankarakter bukan hanya oleh pihak sekolah saja, tetapi juga tanggung jawab orang tua. Ketika di sekolah guru dan kepala sekolah sudah mengkondisikan dengan baik namun akan sangat sulit mengontrol perilaku siswa yang masih menyimpang. Kemudian faktor lain adalah perbedaan budaya di rumah dan di sekolah. Jika di rumah siswa tidak melakukan perbuatan negatif seperti perkelahian tetapi di sekolah mempunyai permasalahan dengan siswa yang lain sehingga terlibat perkelahian.

Khususnya orang tua kadang-kadang ada saja yang kurang memperhatikan anaknya ketika anaknya bermasalah dan kemudian sekolah memberikan surat panggilan, kedua orang tuanya tidak datang ke sekolah tepat pada waktunya, pekerjaan orang tua, dan siswa masih banyak yang kurang paham diarahkan contohnya ketika pada jam sholat berjamaah saja masih harus di giring paksa.Yang terpenting adalah bagaimana guru tidak pernah bosan dalam mengingatkan dan memberikan contoh yang terbaik kepada siswa, karena pendidikan karakter membutuhkan proses yang tidak sebentar dan perlu pengulangan atau pembiasaan. 


\section{Dampak Kebijakan Implementasi Kebijakan Pendidikan Karakter di SMP Negeri 5}

\section{Mataram}

Beberapa dampak pendidikan karakter yang diterapkan di SMP Negeri 5 Mataram adalah: 1) siswa memiliki jiwa cinta tanah air, religius, kompak, dan memiliki jiwa patriotisme; 2) menghasilkan pribadi yang tidak mengabaikan nilai-nilai sosial, seperti toleransi dan tanggung jawab; 3) menciptakan rasa percaya diri untuk menyampaikan pendapat.

\section{Pembahasan}

Hasbullah(2015:92) menjelaskan bahwa implementasi kebijakan pendidikan merupakan proses yang tidak hanya menyangkut perilaku-perilaku badan administratif yang bertanggung jawab untuk melaksanakan program dan menimbulkan ketaatan kepada kelompok sasaran, melainkan juga menyangkut faktor-faktor hukum, politik, ekonomi, sosial, yang langsung atau tidak langsung berpengaruh terhadap perilaku dari berbagai pihak yang terlibat dalam program.

Implementasi kebijakan pendidikan karakter di SMP Negeri 5 Mataram yaitu :

\section{Implementasi Pendidikan Karakter Dalam Kegiatan Pembelajaran}

Implementasi kebijakan pendidikan karakter dalam kegiatan pembelajaran dilihat dari penjabaran nilai-nilai karakter yang ditanamkan oleh guru dalam KBM antara lain : 1) Religius (berdo'a sebelum dan sesudah kegiatan belajar mengajar); 2) Disiplin (masuk kelas tepat waktu, mengumpulkan tugas sesuai jadwal); 3) Jujur (tidak menyontek); 4) Peduli lingkungan (piket membersihkan kelas, berpakaian rapi dan menjaga kebersihan; 5) Tanggung jawab (melaksanan tugas sesuai perintah guru; 6) Kreatif (membuat slogan nilai-nilai moral); 7) Demokratis (ikut mengambil keputusan untuk kontrak belajar); 8) Cinta tanah air (menyanyikan lagu kebangsaan; 9) Toleransi (bekerja dalam kelompok).

\section{Implementasi pendidikan karakter melalui budaya pengembangan sekolah}


Implementasi pendidikan karakter di SMP Negeri 5 Mataram dilaksanakan dengan rutin agar nilai-niai karakter melekat pada diri siswa, pembiasaan rutin di sekolah ini meliputi :

\section{a. Kegiatan Harian}

Kegiatan harian di SMP Negeri 5 Mataram berupa 1) Kegiatan berjabat tangan dengan guru-guru di gerbang ketika siswa berangkat sekolah dan juga pemeriksaan ketertiban serta kelengkapan atribut siswa. 2) Pembacaan ikrar siswa seperti menyanyikan lagu Indonesia Raya; 3) Sholat dhuha yang dilaksanakan oleh guru dan siswa pada saat jam istirahat pertama. 4) Sholat dzuhur berjamaah dilaksanakan oleh seluruh warga sekolah dan 5) Pembiasaan senyum, salam, dan sapa setiap kali bertemu.

\section{b. Kegiatan Mingguan}

Kegiatan minggan di SMP Negeri 5 Mataram berupa 1) Upacara bendera setiap hari Senin; 2) Imtaq pada hari jum'at.

c. Pembiasaan Spontan

Kegiatan ini dilakukan biasanya pada saat guru mengetahui adanya perbuatan yang kurang baik dari siswa yang harus dikoreksi pada saat itu juga. Misalnya, ada siswa yang membuang sampah sembarangan, berteriak-teriak sehingga menganggu pihak yang lain, berbicara dan berlaku tidak sopan.Mengunjungi teman yang sedang tertimpa musibah sakit ataupun keluarganya yang meninggal.

d. Kegiatan Ekstrakulikuler

Kegiatan ekstrakulilkuler merupakan kegiatan yang dilakukan untuk mengembangkan bakat dan minat siswa dan juga bertujuan untuk membentuk karakter siswa. Kegiatan ekstrakulikuler diikuti siswa berdasarkan bakat dan minat siswa itu sendiri tanpa adanya paksaan. Beberapa kegiatan tersebut seperti: pencak silat, pramuka, PMR (Palang Merah Remaja), dan Drum Band. 
Sejalan dengan hasil penelitian ini, menurut Hamid dan Saebani (2013) mengembangkan karakter siswa di sekolah memerlukan program-program sekolah yang secara tegas dan terperinci mendukung terwujudnya karakter tersebut. Membangun karakter siswa tidak cukup hanya melalui mata pelajaran tertentu, tetapi juga melalui semua mata pelajaran yang saling berintegrasi.Terwujudnya pendidikan karakter di sekolah juga membutuhkan dukungan sarana prasarana sekolah yang memadai. Kesadaran tinggi dari semua komponen sekolah untuk merancang programprogram dan mengevaluasi program tersebut.

\section{KESIMPULAN}

Implementasi Kebijakan Pendidikan Karakter di SMP Negeri 5 Mataram dilakukan dengan implementasi pendidikan karakter dalam proses belajar mengejar di dalam kelas, dengan mengembangkan kebiasaan-kebiasaan rutin, spontan, dan kegiatan ekstrakulikuler.Faktor pendukung implementasi kebijakan pendidikan karakter di SMP Negeri 5 Mataram yaitu Faktor intern berupa kesadaran siswa dalam melaksanakan pendidikan karakter. Dan faktor ekstren kerjasama antara guru dan karyawan, lingkungan yang kondusif, dan kegiatan yang sudah terprogram. Faktor penghambat implementasi kebijakan pendidikan karakter di SMP Negeri 5 Mataram, juga meliputi faktor intren dan ekstren. Faktor intren yaitu keberagaman karakter siswa dan keterbatasan guru dalam melaksanakan pendidikan karakter. Sedangkan faktor ekstren yaitu faktor dari orangtua siswa, sarana dan prasana yang kurang memadai.

Dampak implementasi kebijakan pendidikan karakter di SMP Negeri 5 Mataram yaitu : siswa memiliki jiwa cinta tanah air, memiliki jiwa religius, memiliki kekompakan, memiliki jiwa patriotisme, rasa percaya diri, disiplin.

\section{DAFTAR PUSTAKA}

Abidin, Yunus. 2012. Model Penilaian Otentik dalam Pembelajaran Membaca Pemahaman Berorientasi Pendidikan Karakter.Jurnal. Bandung: Universitas Pendidikan Indonesia.

Hamid, Hamdani \& Saebani, B. Ahmad. 2013. Pendidikan Karakter Perspektif Islam. Bandung: Pustaka Setia. 
Jaleha, 2018. Implementasi Kebijakan Sekolah Dalam Menerapkan Pendidikan Karakter Siswa Di Mts Muhammadiyah I Tlogomas Kota Malang. Tesis S2. Universitas Muhammadiyah Malang. Kota Malang.

Mu'in, Fatchul. 2011. Pendidikan Karakter Konstruksi Teoritik dan Praktik. Yogyakarta: Arrruzz Media.

Mulyasa. 2009.Implementasi Kurikulum Tingkat Satuan Pendidikan Kemandirian Guru Dan Kepala Sekolah. Jakarta: PT Bumi Angkasa.

Omeri, Nopan. 2015. Pentingnya Pendidikan Karakter dalam Dunia Pendidikan. Manajer Pendidikan. Volume 9 (3), hal 464-468.

Sulistyowati Endah, 2012. Implementasi Kurikulum Pendidikan Karakter. Yogyakarta: PT Citra Aji Permana.

Zubaedi, 2011. Desain Pendidikan Karakter: Konsepsi Dan Aplikasinya Dalam Lembaga Pendidikan: Jakarta. Kencana Prenada Media Group. 